\title{
FAMILIARES CUIDADORES DE IDOSOS COM SINTOMAS DEPRESSIVOS
}

\section{FAMILY CAREGIVERS OF ELDERLY WITH DEPRESSIVE SYMPTOMS}

\section{FAMILIARES CUIDADORES DE ANCIANOS CON SÍNTOMAS DEPRESIVOS}

\author{
Gabriela Souza Granero ${ }^{1}$, Luan Augusto Alves Garcia ${ }^{2}$, Irma Helena Ferreira Benate Bomfim³, Edna Maria \\ Campanhol $^{4}$, Marta Regina Farinelli ${ }^{5}$, Álvaro da Silva Santos ${ }^{6}$
}

\begin{abstract}
RESUMO
Objetivo: conhecer as relações de cuidado dos familiares de idosos com sintomas depressivos e a suas percepções acerca do desgaste do cuidador. Método: estudo qualitativo, com coleta de dados entre agosto e setembro de 2018, por meio de entrevista semiestruturada, submetidos à an6álise de conteúdo temática e organizados em três categorias. Resultados: participaram três cuidadores familiares. O cuidado empreendido ao idoso com sintomatologia depressiva por familiares é reconhecido como gratificante por poder contribuir com familiar, garantindo o estabelecimento de vínculos, porém este cuidado pode gerar sobrecargas nestes cuidadores. Conclusão: compreender as implicações que norteiam a atividade de cuidado realizada por familiares pode nortear a criação/reorientação de políticas públicas, as quais ofereçam uma rede de suporte e amparo a esses cuidadores, contribuindo para sua qualidade de vida.
\end{abstract}

Descritores: Idoso; Depressão; Familia; Cuidadores.

\begin{abstract}
Objective: to get acquainted the care relationships of family members of the elderly with depressive symptoms and their perceptions about the weariness of the caregiver. Method: qualitative study, with data collection between August and September of 2018, through semistructured interviews, submitted to analysis of thematic content and organized into three categories. Results: three family caregivers participated. The care provided to the elderly with depressive symptoms by family members is recognized as gratifying for providing means to contribute to the family member, which can guarantee establishment of bonds, however this care has the potential to generate overload on these caregivers. Conclusion: understanding the implications that guide the care activity performed by family members can guide the creation/reorientation of public policies, which offer a network of support and support to these caregivers, contributing to their quality of life.
\end{abstract}

Descriptors: Aged; Depression; Family; Caregivers.

\footnotetext{
1 Psicóloga. Mestranda em Psicologia. Programa de Pós Graduação em Psicologia/Universidade Federal do Triângulo Mineiro, Uberaba/MG, Brasil.

${ }^{2}$ Enfermeiro. Es pecialista em Enfermagem do Trabalho, Gestão dos Serviços em Ergonomia, Gestão Pública em Saúde pela Faculdade de Gestão e Negócios da Universidade Federal de Uberlândia (UFU), Saúde do Adulto na modalidade Residência Multiprofissional em Saúde pela Universidade Federal do Triângulo Mineiro - UFTM. Mestre em Atenção à Saúde pela UFTM. Doutorando em Atenção à Saúde pela UFTM.

${ }^{3}$ Psicóloga. Doutora em Psicologia Docente do UNI-FACEF, Franca, SP, Brasil.

${ }^{4}$ Assistente Social. Doutora em Serviço Social. Docente do Uni-FACEF - Centro Universitário Municipal de Franca/SP, Brasil.

${ }^{5}$ Assistente Social. Bacharel em Direito. Mestre e Doutora em Serviço Social. Professora Adjunta IV do Curso de Serviço Social, do Programa de Pós Graduação em Psicologia e, da Residência Integrada e Multiprofissional em Saúde da Universidade Federal do Triângulo Mineiro (RIMS/UFTM), Uberaba/MG/Brasil

${ }^{6}$ Enfermeiro. Pós Doutor em Serviço Social. Profess or Associado do Programa de Pós -Graduação em Psicologia e do Programa de Pós-Graduação em Atenção à Saúde da Universidade Federal do Triângulo Mineiro, Uberaba/MG, Brasil.
} 


\section{RESUMEN}

Objetivo: conocer las relaciones de cuidado de los familiares de ancianos con síntomas depresivos y sus percepciones sobre el uso del cuidador. Método: estudio cualitativo, con recolección de datos entre agosto y septiembre de 2018, a través de entrevistas semiestructuradas, sometidas a análisis de contenido temático y organizadas en tres categorías. Resultados: participaron tres cuidadores familiares. La atención brindada a los ancianos con síntomas depresivos por parte de los familiares se reconoce como gratificante por poder contribuir con los familiares, asegurando el establecimiento de vínculos, pero esta atención puede causar sobrecargas en estos cuidadores. Conclusión: comprender las implicaciones que guían la actividad asistencial realizada por los miembros de la familia puede guiar la creación / reorientación de políticas públicas, que proporcionan una red de apoyo y apoyo para estos cuidadores, contribuyendo a su calidad de vida.

Descriptores: Anciano; Depresión; Familia; Cuidadores.

\section{INTRODUÇÃO}

O envelhecimento populacional brasileiro tem sido acompanhado pelo aumento da prevalência de doenças crônicas não transmissíveis com importantes repercussões nas políticas sociais e de saúde e também idosos com limitações funcionais com necessidade de cuidados constantes de outras pessoas. ${ }^{1}$

No contexto sociocultural brasileiro, nas situações em que os idosos necessitam de cuidados em decorrência dos agravos de saúde cabe a familia o cuidado ao idoso com incapacidades funcionais. Muitas das vezes, estes indivíduos não estão preparados para tal situação, estando frequentemente vivenciando situações de adaptação e enfrentamento a esta nova situação. ${ }^{1}$

Dentre as situações de saúde que acometem os idosos e que podem afetar sua funcionalidade, fazendo com que necessitam de apoio no cuidado a depressão é um agravo bastante frequente. ${ }^{2}$ Cerca de
300 milhões de pessoas em todo mundo possuem sintomatologia depressiva, sendo elevado o acometimento a pessoas de meia idade e a população idosa. ${ }^{3}$

Um dos fatores que podem estar associados ao desencadeamento de depressão pode ser a prestação de cuidados aos familiares. Estudos apontam a alta correlação de cuidado domiciliar e depressão quando o cuidado era prestado a algum familiar. ${ }^{1,2,4}$

O exercício contínuo da tarefa de cuidar interfere na vida dos familiares cuidadores, aumenta a sua sobrecarga e ocasiona problemas físicos, psicológicos e sociais. Deste modo, o esgotamento e a exaustão dos cuidadores, somado a sintomatologia característica de quem sofre a sobrecarga, podem ser resultantes da dedicação ininterrupta, o que leva o cuidador a deixar suas necessidades próprias em segundo plano $^{4}$, por isso é comum os cuidadores queixarem-se 
frequentemente de depressão, estresse, ansiedade e sobrecarga. ${ }^{2}$

Existem dois tipos de sobrecarga, a objetiva, relacionada à mudança de rotina, realização de tarefas, diminuição da vida social e profissional dos cuidadores, que por sua vez, podem ocasionar uma sobrecarga subjetiva, que se refere aos sentimentos negativos, preocupações e incômodos derivados das tarefas desempenhadas, sendo assim, os cuidadores profissionais tendem a vivenciar mais a sobrecarga objetiva, enquanto os cuidadores informais sentem maior sobrecarga subjetiva. ${ }^{3}$

Ao se considerar os aspectos relacionados à sobrecarga e desconforto emocional do cuidador familiar, compreender como estes sintomas relacionam à tarefa do cuidar de idosos com sintomatologia depressiva pode permitir uma melhor compreensão do fenômeno e facilitar o processo de planejamento do cuidado. É de extrema importância a adoção de medidas que minimizem os desconfortos decorrentes da tarefa de cuidado familiar ao idoso dependente, minimizar a intensidade e diversidade de sentimentos que possam surgir nessa tarefa. Ademais, há de se destacar poucos estudos realizados com cuidadores secundários e principalmente relacionados às estratégias promotoras de saúde mental aos cuidadores informal de idosos.
Nesta perspectiva, este estudo objetivou conhecer as relações de cuidado dos familiares de idosos com sintomas depressivos e suas percepções acerca do desgaste do cuidador.

\section{MÉTODO}

Trata-se de uma pesquisa exploratória e de recorte transversal, com abordagem clínico-qualitativa. Foram convidados a participar do estudo os familiares cuidadores dos idosos que frequentavam duas unidades básicas de saúde da cidade de Uberaba, Minas Gerais.

Os critérios de inclusão para participação do estudo foi ser o principal familiar cuidador primário de idoso com presença de sintomatologia depressiva. Os familiares cuidadores que apresentaram algum declínio cognitivo não participaram do estudo. O déficit cognitivo foi avaliado pelo Mini exame do Estado Mental, desenvolvido originalmente por Folstein e colaboradores $^{5}$ e validada para a população brasileira por Almeida. ${ }^{6}$

A escolha das unidades básicas de saúde se deram por serem unidades matriciais em saúde no município, em que cada uma delas possui três equipes de saúde da familia cada uma, o que possibilitou uma amostragem mais heterogênea e representativa, haja vista a elevada prevalência de idosos com sintomatologia depressiva identificada em estudo prévio. ${ }^{7}$ 
O critério de amostragem se deu por conveniência $^{7}$, participando três familiares cuidadores primários de idosos com sintomas depressivos respectivamente, leve, moderado e grave, constatado pela Escala de Depressão Geriátrica (GDS-15) validada para a população brasileira. ${ }^{8}$

Após a autorização da coordenação das referidas unidades foi realizada na sala de espera o recrutamento dos idosos com sintomatologia depressiva. Foram abordados 23 idosos em que foram aplicados os instrumentos de rastreio de declínio cognitivo e indicativo de depressão. Oito idosos obtiveram pontuação igual ou acima de cinco pontos na escala de depressão geriátrica, classificando-se com indicativos de pressão, sendo quatro com sintomas leves, dois com sintomas moderados e dois com sintomas graves.

Após o processo de recrutamento dos idosos com sintomatologia, foi realizado agendamento prévio com idoso para uma visita domiciliar para que a etapa de entrevistas com o cuidador fosse realizada.

Do total de oito idosos recrutados inicialmente, cinco foram excluídos por não se enquadrarem nos critérios de inclusão do estudo: residiam sozinhos (um idoso), não possuíam familiares como cuidador principal (dois idosos), não foram encontrados na residência (um idoso) e não concordaram em participar do estudo (um idoso).

Os familiares cuidadores foram convidados a participarem do estudo, realizando entrevistas individuais abertas com a seguinte questão norteadora: Conteme como é cuidar do idoso que você convive?

As entrevistas foram realizadas no período de agosto a setembro de 2018, na própria residência dos participantes, em um cômodo silencioso a de resguardo ao sigilo ético. Os participantes foram denominados por nomes fictícios para a garantia do anonimato dos mesmos.

Os encontros foram áudios gravados e transcritos, e os dados analisados em profundidade através da técnica análise de conteúdo temático, por meio das três etapas a saber: pré-análise, exploração do material e tratamentos dos resultados (inferência e interpretação). ${ }^{9}$

O presente estudo foi aprovado pelo ao Comitê de Ética em Pesquisa da Universidade Federal do Triângulo Mineiro, parecer número 2.769.433.

\section{RESULTADOS}

$$
\text { Foram entrevistados três }
$$
participantes cuidadores de idosos com sintomas depressivos. O primeiro era uma mulher Betina (43 anos) filha de uma idosa, classificada com sintomas depressivos leves (05 pontos-GDS15), o segundo é o Salvador (51 anos) filho de uma idosa com sintomas 
depressivos moderados (08 pontosGDS15), e a terceira é Antônia (78 anos), irmã de uma idosa, com sintomas depressivos graves (10 pontos-GDS15).

Através da análise de conteúdo temática foram emergiram três categorias das entrevistas realizadas, a saber: (1) Cuidador suficientemente bom e a possibilidade de um ambiente facilitador aos idosos com sintomas depressivos; (2) O familiar cuidador e o fortalecimento da autonomia durante o envelhecimento e (3) Sobrecarga subjetiva e a necessidade de implementação de políticas públicas aos cuidadores informais.

As categorias foram elencadas por meio dos elementos em comum segundo o critério de relevância e, agrupados por conteúdos semanticamente semelhantes que respondem ao objetivo do estudo.

Categoria 1 - Cuidador suficientemente bom e a possibilidade de um ambiente facilitador aos idosos com sintomas depressivos

Nessa categoria foi possível identificar como se dão as relações afetivas entre os cuidadores e idosos com sintomas depressivos. Os participantes relataram:

Vai por uma roupa nova, bonitinha só porque vai sair, tem que fazer a unha pra ficar dentro de casa, cortar o cabelo, o cabelo dela era vermelho, agora ela mudou o visual, é bom cuidarde idoso, eu tenho muita paciência, né mãe?!...não adianta, idoso é três coisas que tem que ter, tempo, amor e dedicação, não existe outras coisas (Betina).

Porque eu queria que ela fosse se cuidar, como toda idosa, ir lá dançar forró, fazer hidroginástica, fazer amizade com outras pessoas, não ficar só nesse mundo, eu queria que ela fizesse amizade, cuidasse dela, do cabelo, não preocupasse, eu penso assim, eu quero ver minha mãe bem (Salvador).

Quando ela está aqui é bom, é bom, ela fica feliz, melhora né? aqui ela quase não reclama, eu acho que é porque ela fica lá sozinha, ela fica aqui desde que o marido morreu, qualquer coisa ela corre pra cá, se ela tá com medo, se ela tá doente, ela corre pra cá, agora que nossa irmã morreu ela ficou mais triste, mas ela vem há muitos anos, há 5 anos (Antônia).

Categoria 2 - Os familiares cuidadores e o fortalecimento da autonomia durante $\mathrm{o}$ envelhecimento

Essa categoria enfatiza a importância do cuidador fortalecer a autonomia do idoso, sem deixar de oferecer os cuidados necessários. Os cuidadores (as) ressalvaram:

Até domingo ela arrumou pra ir dançar, eu falei assimeu deixo à senhora lá, a senhora pega um moto taxi pra vir embora, porque eu não vou ter condições, porque eu também não dirijo, ela falou assim, daqui uns dias os vizinhos vai começar a falar, respondi, quempaga as contas da senhora éa senhora, eu também não esquento muito com o que vizinho fala (Betina). 
Eu quero que minha mãe seja feliz, entendeu? eu queria que ela largasse essas coisas de sopa, queria que ela participasse, mas pelo menos uma vez no mês ou duas vezes, quero que ela vá em outros lugares (Salvador).

Também morar na casa dos outros é muito ruim né, não tiro a razão dela não, eu só queria que ela tivesse uma companhia fixa, às vezes melhorava essa depressão dela. Mas tem razão né, a casa da gente é outra coisa, não sou contra não! Mas por mim, ela não ia e morava no meu quarto, mas ela não aceita (Antônia).

Categoria 3 - Sobrecarga subjetiva e a necessidade de implementação de políticas públicas aos cuidadores informais

O cuidado gera uma dependência emocional que tem repercursão sobre a saúde do familiar, ocasionando sobrecarga subjetiva. Os familiares cuidadores disseram:

Eu tinha acabado de voltar do hospital, o médico falou que era pra eu ficar de repouso, pingando colírio, não tava enxergando nada, minha mãe chegou mais ou menos uma hora e eu tive arrumar almoço pra ela, ninguém faz nada, não eu não tenho quem faz nada pra mim, se eu não fazer ninguémfaz. Eu acho importante você focar no idoso quem sabe isso chega nos postinhos, fazer um grupo de idoso, não pra ir lá medir pressão, não! Recreação pra idoso estou falando nos bairro (Betina).

Eu tive uma recaída recentemente e minha mã, ela sente muito porque ela já foi alcoolatra, o que acontece quando a gente recai, quando você recai é complicado e eu acho que isso afeta muito ela, então eu penso em mim mesmo, mas eu penso nela também, eu quero que ela viva bem, não que eu quero mudar pra mim ter minha vida, eu quero mudar pra ter o meu cantinho que nem eu tinha (Salvador).

Ela não tem um gênio muito bom, mas não me cansa de jeito nenhum: eu me sinto cansada agora que tenho hemodiálise, eu fico mais é quieta, eu vou um dia sim e outro não, mas cozinhar, isso tudo eu faço, só não faço trabalho pesado (Antônia).

\section{DISCUSSÃO}

Quando os idosos envelhecem, algum familiar cuidador irá proporcionar esses cuidados, por sua vez, o cuidador é chamado a fazer um trabalho psíquico similar com o da mãe/continente, acolher e dar sentido aos sentimentos, sem reagir a eles, com os recém-nascidos a mãe (ou a substituta) é a que promove os cuidados iniciais. ${ }^{10}$

A primeira experiência de vínculo cria uma condição de estruturação psíquica e na relação com o outro, o humano se constitui como sujeito. Essa situação vivenciada pelo bebê é diferente da situação de dependência do idoso, porque este já tem a base de sua personalidade formada e tem maiores possibilidades de significar sua situação de dependência e cuidado, porém, experiências primitivas de medo, confiança, prazer, ódio e amor, vividas na primeira relação de cuidado, ficam como uma matriz para vivências posteriores. ${ }^{10}$

Todos os participantes com sintomas depressivos desse estudo tem 
algum principal familiar cuidador primário que se dispõe a oferecer os cuidados necessários, entretanto, cada qual oferece tais cuidados de acordo com sua maturidade emocional. Os cuidadores dentro de suas limitações buscaram ofertar um ambiente facilitador para os idosos, no entanto, nem sempre as condições ambientais suprem as necessidades desses idosos com sintomas depressivos.

Os familiares cuidadores dessa pesquisa demonstraram promover um ambiente facilitador, mas pode-se notar que a primeira interlocutora, tem uma maturidade maior e consegue promover $u m$ ambiente suficientemente bom, enquanto o segundo, embora seja muito consciente da sua condição emocional, e incentive a sua mãe a cuidar mais de si, a sua dependência química, o coloca em posição de vulnerabilidade e impossibilidade de oferecer cuidados. Já a terceira, também se encontra fragilizada por ter uma idade semelhante à da idosa que cuida (irmã) e com problemas de saúde, não sendo possível ser o continente necessário. Podese correlacionar o segundo e terceiro cuidadores familiares a um papel de cuidador não conscientemente integrado e pessoalizado, como se pode-observar em mães adoecidas. ${ }^{10}$

Um ambiente facilitador é necessário para a construção do si mesmo individual de um ser humano, mas é possível que esse ambiente facilitador potencial possa não se efetivar, a família precisa ser vista como algo que, reconhece as necessidades do indivíduo, para fornecer as condições à sua satisfação, uma família com um bom potencial à saúde, não está isenta de conflitos, mas é capaz de facilitar o crescimento emocional de seus membros, encontrando caminhos para solucionar seus problemas. ${ }^{10}$

Winnicott foi o fundador dos termos ambiente não suficientemente bom, que distorce o desenvolvimento do bebê, assim como o ambiente suficientemente bom, que possibilita alcançar, a cada etapa, as satisfações, ansiedades, e conflitos inatos e pertinentes de cada fase do amadurecimento. Para esse psicanalista e pediatra o fornecimento de um ambiente suficientemente bom na fase mais primitiva capacita o bebê a começar a existir, a ter experiências, a dominar os instintos, a defrontar-se com todas as dificuldades inerentes à vida, e a constituir um ego pessoal. ${ }^{11}$

O desenvolvimento é uma função da herança de um processo de maturação, e da acumulação de experiência de vida, mas esse só pode ocorrer num ambiente propiciador, é o ambiente circundante que torna possível o crescimento, sem uma confiabilidade ambiental mínima, o crescimento não pode se desenrolar, ou desenrola-se com distorções. ${ }^{11}$ 
O mesmo se dá na fase do envelhecimento, se o familiar cuidador se adapta as necessidades como no caso da primeira cuidadora. As tendências a um bom desenvolvimento e com menor incisão de sintomas depressivos são evidentes, ainda que a idosa tenha passado por acontecimentos traumáticos. Essa primeira cuidadora recorda o sentido do amor maternal que faz com que o bebê se desenvolva saudavelmente, e se encaixa perfeitamente na cuidadora suficientemente boa, de modo que ao mesmo tempo em que a cuidadora familiar gratifica sua mãe, ela frustra na mesma proporção.

Porém quando o ambiente facilitador é mais confuso e tumultuado como no caso do segundo familiar cuidador onde a intensidade de suas angústias e o vício em drogas lícitas o impede que ele oferte os cuidados necessários a sua mãe, o cuidador se assemelha a mãe que é incapaz de ser continente para o bebê.

Já com relação à terceira cuidadora o ambiente é inconstante, ora ela está convivendo com as irmãs, ora ela está sozinha e solitária na sua casa, essa ausência de constância aumenta ainda mais seus sintomas depressivos, ainda que sua irmã tente fornecer as provisões necessárias. Como pode ser observado foi transposto um paralelo entre a teoria do desenvolvimento emocional focado nas relações mãe-bebê, mas na última fase do desenvolvimento humano, a velhice, onde os idosos também recebem influência do ambiente e das relações.

Nesse sentido, o desenvolvimento do ser humano só cessa com a morte. O indivíduo desenvolve-se e torna-se maduro e, não se pode considerar a maturidade adulta como separado do desenvolvimento anterior. Este desenvolvimento é extremamente complexo, e ocorre, desde o nascimento, ou desde antes, passando pela idade adulta, até a velhice. A existência de um processo contínuo de desenvolvimento emocional permanece por toda a vida, até a morte natural. ${ }^{12}$

Nos três familiares cuidadores é possível notar um esforço em ofertar cuidados suficientemente bons aos idosos, à primeira cuidadora incentiva o lazer, diversão e cuidado com o corpo; o segundo sugere melhores hábitos, terapia e diversão e, a terceira incentivando que a cuidanda morasse com ela, mas a primeira cuidadora é a que oferece um holding com maior eficiência, com maior habilidade emocional em suprir as necessidades da mãe.

Quando se atinge a idade adulta, há relativa autonomia e independência do cuidado do outro, porém, com o envelhecimento, a situação de dependência, desamparo e necessidades de cuidados retorna e será determinada pela qualidade de experiência de cuidados anteriores. ${ }^{13}$ Assim, o primeiro cuidador, geralmente é a 
mãe, e para o idoso têm-se substitutos como os familiares, os profissionais ou mesmo alguma instituição. ${ }^{14}$

Os idosos por causa do processo de senescência tendem a serem tratados como uma criança indefesa, porém é importante que o cuidador o auxilie na conquista da independência. Lidar com angústia e com os aspectos sombrios do envelhecimento, juntamente com as perdas da funcionalidade do corpo, cognitivas e dependência física faz com que os cuidadores utilizem mecanismos de defesa do $\mathrm{Eu}$, a fim de protegeram sua saúde mental frente a um cotidiano rude, e um dos mecanismos utilizados é a infantilização dos idosos, que permite ao cuidador proteger-se do fato de que aquele idoso é um adulto, e o ajuda e encarar essa realidade. ${ }^{12}$

$\mathrm{Na}$ segunda categoria desse estudo, na qual a autonomia pressupõe criar um ambiente acolhedor onde o idoso possa manifestar sua vontade sem ter sido submetido à coação, influência, indução ou intimidações dos cuidadores, familiares ou profissionais da saúde, ou seja, a presença do cuidador ou profissional de saúde que inspira confiança e considere a singularidade do envelhecimento e da identificação de suas necessidades o que pode contribuir muito à qualidade de vida do idoso. ${ }^{10}$
Muitos idosos sentem desconforto em relação às vivências de fragilidade e dependência, o envelhecimento não é uma doença, por isso, o idoso deve se perguntar, o que fazer para que a vida tenha sentido, e a resposta deveria ser sentir-se vivo, com a sensação interna de preenchimento e não de vazio, ter um propósito em sua existência, e não ficar esperando a chegada da morte. ${ }^{13}$

Por esses motivos, os cuidados proferidos pelos familiares poderiam seguir como princípio a instrumentalização dos envolvidos para a execução de tarefas que visem à independência a á humanização, pois estes princípios favorecem $o$ reconhecimento da autonomia de quem envelhece, por isso, cuidar rumo autonomia é uma tarefa complexa que exige preparo por parte dos profissionais e dos familiares, já que altera o conceito de cuidado. ${ }^{14}$

Muitos nutrem o medo de atrapalhar a vida dos seus cuidadores, frequentemente os papéis se misturam e as identidades dos idosos versus cuidadores são afetadas e, com o tempo sentem-se angustiados. Por sua vez, a partir do momento que aquele que cuida perde suas referências pessoais, elimina seus desejos e necessidades, pensa que está cumprindo seu papel, mas a tarefa do cuidar se torna mais penosa. ${ }^{15}$

A visão centrada na figura do idoso como alguém fragilizado e incapaz, deve ser gradualmente substituída por uma perspectiva do envelhecimento positivo, 
oferecendo uma releitura dessa fase do ciclo vital. É importante potencializar intervenções baseadas nos aspectos positivos dos idosos, nas suas capacidades de vinculação, em seus recursos e na releitura daquele que vem a ser cuidado. ${ }^{15}$

Os três familiares cuidadores desse estudo contribuem para manutenção da autonomia dos idosos. A primeira familiar é a que mais oferece cuidados a sua mãe, percebe-se um cuidado mais intensificado que se descuidado pode se tornar dependente e sufocante, e apesar das (cuidadora e cuidanda) aparentemente possuírem uma relação simbiótica, também permite certa liberdade a cuidanda o que amplia a capacidade relacional e autonomia da idosa.

O segundo cuidador deseja que sua mãe não vá fazer sopa com tanta frequência, inconscientemente ele não permite que a cuidanda realize seus desejos e rompe com a autonomia da idosa, porém por outro lado em seu discurso incentiva a mãe a buscar meio de se realizar. A terceira cuidadora respeita o anseio da sua irmã de morar em sua própria casa e ter seu canto e demonstra empatia em acatar o desejo da irmã, em contraposição ela não a deixa desamparada, trazendo-a para perto de si e ofertando cuidados.

Adentrando na terceira categoria é comum que os cuidados primários de um membro da família de idosos com transtornos mentais são particularmente difíceis, exigentes e tem consequências adversas para a saúde. Os cuidadores devem adotar uma gama complexa de estratégias de enfrentamento para reforçar a sua própria resiliência. ${ }^{16}$ Quem cuida muitas vezes adoece mais do que o próprio ser cuidado, o excesso de afazeres e constante dedicação, adoece o cuidador, que coloca sua vida em segundo plano. ${ }^{15}$ A atitude de cuidado provoca preocupação, inquietação e sentido de responsabilidade pela vida do outro, o cuidar é muito exigente e pode levar o cuidador ao estresse, especialmente quando o cuidado, não é um ato esporádico, e sim uma atitude permanente. ${ }^{15}$

Assim, como os cuidadores são seres limitados, sujeitos ao cansaço, fracassos e decepções, muitas vezes, sentem-se sós, e por isto, também precisam de cuidados, caso contrário à vontade de cuidar se enfraquece, e a boa energia que se irradia do cuidado deixa de corroborar na cura. ${ }^{15}$ Os idosos muitas vezes projetam nos familiares ou na equipe de saúde seus sentimentos, transferem, revivem e transformam afetos em conflitos. ${ }^{13}$ Essas transferências inconscientes sobre $\mathrm{O}$ cuidador, os sobrecarregam, quando os idosos possuem sintomas depressivos como os interlocutores dessa pesquisa, a projeção de sentimentos ambivalentes, confusos, raivosos e pessimistas são ainda mais acentuados. 
Os três cuidadores desses estudos evidenciaram aspectos de que o cuidar é uma tarefa exigente, mas eles ainda não se encontram esgotados. Uma das alternativas possíveis para minimizar a sobrecarga é instituir uma rotina de revezamento entre os familiares, permitindo ao cuidador principal alternar os cuidados com outros membros, para que consiga restabelecer suas necessidades de descanso e repouso, no entanto essa estratégia ainda não faz parte do cotidiano da maioria das famílias acompanhadas. ${ }^{17}$

Estudo que avaliou a sobrecarga de cuidadores informais de idosos com déficit cognitivo de Ribeirão Preto/SP identificou o declínio cognitivo como preditor para sobrecarga e desconforto emocional de seus cuidadores familiares. ${ }^{18}$

Ao avaliar a sobrecarga de cuidadores familiares de um cantão de Chordeleg (Equador) evidenciou elevada prevalência de sobrecarga nos cuidadores, com associação a possuir mais de cinco anos como cuidador e incapacidade moderada a severa do idoso. ${ }^{19}$ Estudo longitudinal sobre envelhecimento coreano identificou maiores chances de acometimento de sintomatologia depressiva entre cuidadores familiares que necessitam de cuidados para as atividades de vida diárias. $^{2}$

Ao avaliar as situações positivas e negativas vivenciadas por cuidadores familiares de idosos atendidos em um Serviço de Atenção Domiciliar apontam que as situações negativas relacionadas ao cuidado empreendido relacionam inexperiência prévia e desconhecimento de tecnologias utilizadas para o cuidado; estar sozinho para o cuidado e alterações psicofisiológicas do cuidador. As situações positivas sintetizam o conforto de estar em casa, apoio do Serviço de Atenção Domiciliar e redução nos gastos com deslocamento até serviço de saúde. ${ }^{20}$ Embora o desprendimento para o cuidado no domicilio do um idoso seja uma situação desafiadora, muitas das vezes pode gerar aspectos de conforto para o cuidador em manter o idoso em seu domicílio e garantir ao mesmo melhor qualidade de vida.

Por isso, a importância de realizar estudos que investiguem o perfil de cuidadores familiares, e as implicações que norteiam a atividade realizada por esses sujeitos se dá na medida em que podem possibilitar a criação de políticas públicas, as quais ofereçam uma rede de suporte e amparo a esses cuidadores, contribuindo para sua qualidade de vida. É preciso oferecer sustentáculo aos familiares, visando à redução de sobrecarga dos cuidadores que ficam em tempo integral e ações de cuidados com vistas ao fornecimento de suportes formais aos cuidadores. ${ }^{16}$ 
Para os idosos e seus familiares deve ser oferecida uma assistência humanizada para identificar e avaliar as suas necessidades com a intenção de fornecer melhores condições de saúde e planejar ações de atenção, principalmente em relação aos sintomas depressivos em idosos e sobrecarga de seus familiares cuidadores. ${ }^{17}$

\section{CONCLUSÃO}

$\mathrm{O}$ estudo permitiu conhecer às relações dos familiares cuidadores de idosos com sintomas depressivos. Percebese que os três familiares cuidadores evidenciaram falta de suporte social por outros integrantes da família, os cuidadores primários tendem a ficar mais sobrecarregados, enquanto os secundários dispõem pouco tempo com os idosos, constituindo-se em relações afetivas distantes e descompromissadas. O estudo revela pouco revezamento entre os membros da família.

A principal limitação desse estudo refere-se às características especificas dessa amostra, número reduzido de familiares cuidadores. Os resultados não permitem generalizações, sugere-se a ampliação dos dados em pesquisas futuras. Salienta-se a necessidade de criação de políticas públicas aos familiares de idosos e a implementação de ações cuidativas.

\section{REFERÊNCIAS}

1. Couto AM, Caldas CP, Castro EAB. Home care for elderly dependents provided by family caregivers experiencing overload and emotional distress. J Res: fundam care [Internet]. 2019 [citado em $02 \mathrm{dez} 2019$ ]; 11(4):944-50. Disponível em: http $/ /$ www.seer.unirio.br/index.php/cuidad ofundamental/article/view/6782/pdf

2. Kwon J, Park E, Kim W, Choi D, Jang

S. Depressive symptoms in individuals with family members requiring $\mathrm{ADL}$ assistance. Environ Health Prev Med. [Internet]. 2019 [citado em $02 \mathrm{dez} 2019$ ]; 24:49. doi: https://doi.org/10.1186/s12199019-0804-x

3. World Health Organization. Depression and other common mental disorders: global health estimates [Internet]. Geneva: WHO; 2017 [citado em 02 dez 2019]. 21p.

Disponível em: https:/apps.who.int/iris/bitstream/handle/1 0665/254610/WHO-MSD-MER-2017.2eng.pdf

4. Kim BJ, Liu L, Nakaoka S, Jang S, Browne C. Depression among older Japanese Americans: the impact of functional (ADL \& IADL) and cognitive status. Soc Work Health Care. 2018; 57(2):109-25.

5. Folstein MF, Folstein SE, McHugh PR. Mini-Mental State: a practical method for grading the cognitive state of patients for the clinician. J Psychiat Res. 1975; 12(3):189-98.

6. Almeida OP. Mini exame do estado mental e o diagnóstico de demência no Brasil. Arq Neuropsiquiatr. 1998; 56(3B):605-12.

7. Hajjar R, Nardelli GG, Garcia LAA, Gaudenci EM, Santos ÁS. Quality of life and depressive symptoms among elderly in primary care. Biosci J. [Internet]. 2018 [citado em 3 dez 2019]; 34(6):1733-43. doi: https//doi.org/10.14393/BJv34n6a2018-39875

8. Almeida OP, Almeida AS.

Confiabilidade da versão brasileira da escala de depressão em geriatria (GDS) 
versão reduzida. Arq Neuropsiquiatr. 1999; 57(28):421-6.

9. Turato ER. Tratado da metodologia da pesquisa clínico-qualitativa: construção teórico-epistemológica, discussão comparada e aplicação nas áreas da saúde e humanas. 6 ed. Rio de Janeiro: Vozes; 2013.

10. Cherix K, Coelho Júnior, NE. O cuidado de idosos como um campo intersubjetivo: reflexões éticas. Interface (Botucatu) [Internet]. 2017 [citado em 29 jun 2019]; 21(62):579-88. doi: http://dx.doi.org/10.1590/180757622015.0492

11. Dias EO. A teoria do amadurecimento de D.W. Winnicott. 3 ed. São Paulo:

DWW editorial; 2014.

12. Kreuz G, Franco MHP. Reflexões acerca do envelhecimento, problemáticas, e cuidados com as pessoas idosas. Rev Kairós [Internet]. 2017 [citado em 29 jun 2019]; 20(2):117-33. doi: https://doi.org/10.23925/2176901X.2017v20i2p117-133

13. McCann TV, Bamberg J, McCann F. Family carers' experience of caring for an older parent with severe and persistent mental illness. Int J Ment Health Nurs. [Internet]. 2015 [citado em 29 jun 2019]; 24(3):203-12. doi:

https://doi.org/10.1111/inm. 12135

14. Couto AM, Castro EA, Calda CP. Vivências de ser cuidador familiar de idosos dependentes no ambiente domiciliar. Rev Rene [Internet]. 2016 [citado em 29 jun. 2019]; 17(1):76-85. doi: https://doi.org/10.15253/2175-

6783.2016000100011

15. Hedler HC, Paula Faleiros V, Santos MDJS, Araújo Almeida MA

Representação social do cuidado e do cuidador familiar do idoso. Rev Katálysis [Internet]. 2016 [citado em 29 jun 2019]; 19(1):143-53. doi:

http://dx.doi.org/10.1590/141449802016.00100015

16. Aires M, Mocellin D, Fengler FL, Rosset I, Santos NO, Machado DO, et al. Associations between filiar responsibility when caring for parentes and the caregivers overload. Rev Bras Enferm. [Internet]. 2017 [citado em 29 jun 2019]; 70(4):767-74. doi: http $/ /$ dx.doi.org/10.1590/0034-7167-20170133

17. Girardi-Paskulin LM, KottwitzBierhals CCB, Oliveira dos Santos N, Baltar-Day C, Oliveira-Machado D, Pinheiro de Morais E, et al. Depressive symptoms of the elderly people and caregiver's burden in home care. Invest Educ Enferm. [Internet]. 2017 [citado em 29 jun 2019]; 35(2):210-20. doi:10.17533/udea.iee.v35n2a10 18. Gratão ACM, Talmelli LFS, Haas VJ, Marques S, Kusumota L, Rodrigues RAP. Assessment of caregiver burden with elderly having cognitive déficit. Acta Paul Enferm. [Internet]; 2012 [citado em 2 dez 2019]; 25(6):908-13. doi: http $/ / d x$. doi.org/10.1590/S010321002012000600013 19. Alexandra COP, Paola OOK. Síndrome de sobrecarga en cuidadores familiares de adultos mayores y factores asociados. Chordeleg, 2017. Rev Fac Cienc Méd Univ Cuenca [Internet]. 2019 [citado em $2 \mathrm{dez}$ 2019]; 37(1):11-19. Disponível em: https://doi.org/10.18537/RFCM.37.01.02 20. Silva MS, Beuter M, Benetti ERR, Bruinsma JL, Donati L, Girardon-Perlini NMO. Situações vivenciadas por cuidadores familiares de idosos na atenção domiciliar. Rev Enferm UFSM. [Internet]. 2019 [citado em 02 dez. 2019]; 9(e10):121. doi: https://doi.org/10.5902/2179769232528

RECEBIDO: 02/07/2019

APROVADO: 04/03/2020

PUBLICADO: 07/2020 